\title{
The Influence of Surface Roughness on Laser Beam Welding of Aluminium Alloys
}

\author{
Michaela LOPATKOVÁ, Jozef BÁRTA*, Milan MARÔNEK, Filip ŠUGRA, Michela KRITIKOS, Ivan SAMARDŽIĆ, Dejan MARIĆ
}

Abstract: A laser beam is the light that is subject to the laws of physics. Surface roughness can cause that the light can be reflected in different angles. Therefore, the surface roughness may influence the amount of light to be reflected so the power of the laser could be lowered. Present paper analyses the influence of different surface roughness on porosity and geometry of weld joint using design of experiment. Surface roughness monitored during the experiment was in the range from $R a .8$ to $R a 15$ achieved and by machining on aluminium-lithium alloy AW2099. In order to keep the same condition for welding the bead on plate welds were realised. Porosity was analysed using computer tomography. Surface roughness proved to have minor influence on porosity as well as the shape of the weld joint.

Keywords: computed tomography; laser beam welding; porosity; surface roughness

\section{INTRODUCTION}

Nowadays the aluminium alloys are considered one of the best and mostly used construction material in the industry. They replace steels in many applications because of their specific mechanical and corrosion resistance properties as well as low density. As a construction material aluminium alloys must have good weldability especially for progressive welding technologies that can be applied in mass production. One of these technologies is laser beam welding, where porosity of weld metal is a very common problem.

Authors usually agree on the necessity of removal of oxidic layer as a source of porosity, the other ones refer to technology modifications in order to lower the porosity in weld metal. Standard ways to remove the oxides are mechanical techniques using abrasives, or machining, however there is a risk to impress the inclusions coming from sandpaper into the surface. More innovative approach is to use the laser beam to clean the surface prior to welding. According to results from Zhou at al. [1], the laser cleaning pre-treatment can effectively improve the quality of the surface formation of the aluminium alloy weld (Fig. 1). Laser cleaning in air/argon can greatly reduce the weld seam porosity of the aluminium alloy. The weld seam porosity of the aluminium alloy after laser cleaning in argon is the lowest [1].

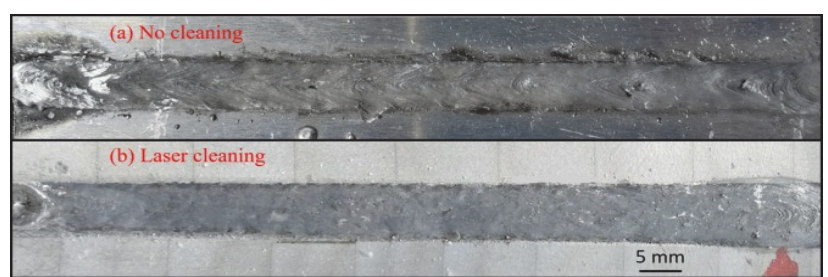

Figure 1 Top view of laser beam weld on laser cleaned surface [1]

Most recommendations related to technology modifications rely on laser beam oscillation with very high frequency what creates wider molten pool and brings higher stability to welding process. Negative effect of beam oscillation is humping (Fig. 2) on the weld joint surface. The porosity lower than $2 \%$ (Fig. 3) was achieved by $200 \mathrm{~Hz}$ oscillation on diameters bigger than $2 \mathrm{~mm}$ (circular oscillation). The biggest issue in using the oscillation is the loss of the penetration depth and thus much more output power to get the original penetration from single pass weld is required $[2,3]$.

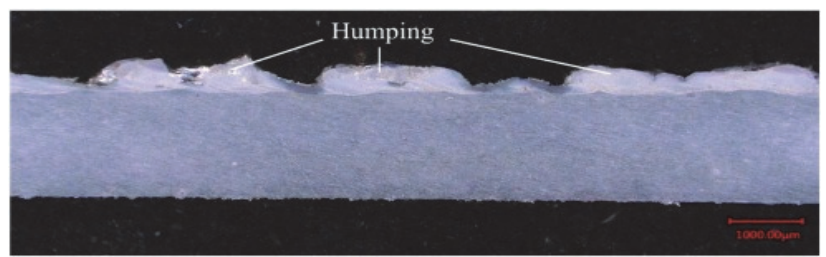

Figure 2 Longitudinal section view with humping [2]

\begin{tabular}{|c|c|c|c|}
\hline Oscillation parameters & $\mathrm{X}$-ray radiography & Porosity & Weld depth \\
\hline Without oscillation & & $42.5 \%$ & $8.3 \mathrm{~mm}$ \\
\hline Without oscillation & 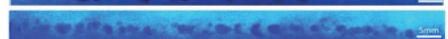 & $29.3 \%$ & $4.5 \mathrm{~mm}$ \\
\hline Without oscillation & 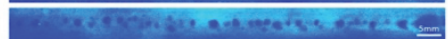 & $26.7 \%$ & $3.9 \mathrm{~mm}$ \\
\hline $1 \mathrm{~mm} / 100 \mathrm{~Hz}$ & 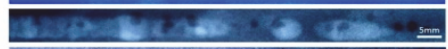 & $24.8 \%$ & $6.3 \mathrm{~mm}$ \\
\hline $1 \mathrm{~mm} / 200 \mathrm{~Hz}$ & 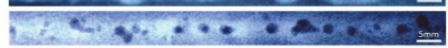 & $21.8 \%$ & $5.9 \mathrm{~mm}$ \\
\hline $1 \mathrm{~mm} / 300 \mathrm{~Hz}$ & 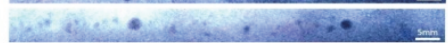 & $13.3 \%$ & $4.9 \mathrm{~mm}$ \\
\hline $2 \mathrm{~mm} / 100 \mathrm{~Hz}$ & 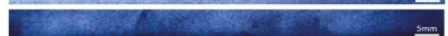 & $3.5 \%$ & $5.6 \mathrm{~mm}$ \\
\hline $2 \mathrm{~mm} / 200 \mathrm{~Hz}$ & & $<2 \%$ & $4.2 \mathrm{~mm}$ \\
\hline $3 \mathrm{~mm} / 300 \mathrm{~Hz}$ & & $<2 \%$ & $3.7 \mathrm{~mm}$ \\
\hline
\end{tabular}

Figure 3 Top view of laser beam weld on laser cleaned surface [3]

The main idea behind the oscillation is the keyhole stability and its collapse when the molten pool is big enough and has a lot of space to flow. Aluminium in liquid state will pour into the keyhole and the porosity will get stacked at the bottom part of the weld because of high cooling rate (Fig. 4).

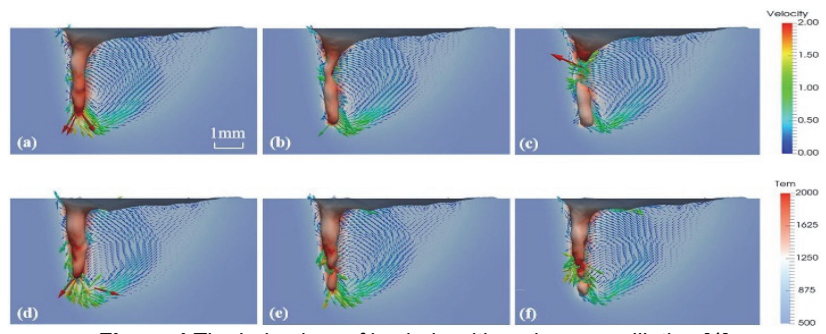

Figure 4 The behaviour of keyhole with no beam oscillation [4]

Liu at al. used ultrasonic power to reduce the oxidation. They concluded that the increase of ultrasonic power leads to lowering of porosity. Their results showed increased tensile strength of samples with increase of ultrasonic power as well as shifting the tensile fracture from weld metal to heat affected zone [5]. 
Han at al. in their research concluded that fatigue strength was reduced from $113 \mathrm{MPa}$ to $56 \mathrm{MPa}$ when the porosity rate increased from $0 \%$ to $8.9 \%$, and the porosity position had little effect on it. The fracture crack initiated in the weld surface when there was no porosity in the joint, and the fracture cracks occurred near the porosity edges when the porosities appeared in the weld seam, particularly near the larger porosity [6].

Porosity in aluminium alloys is still a big topic and many people underestimate the surface cleaning. Proper cleaning can influence the mechanical properties because of lack of impurities and oxides in weld metal caused by porosity coming mostly from grease and moisture that is burnt in arc during the welding process $[7,8]$.

The influence of surface roughness on meltpool dimensions of stainless steel and aluminium during $\mathrm{CO}_{2}$ laser beam processing was investigated by Obeidi et al. [9]. Their results revealed that the increased surface roughness led to considerable increase of the meltpool due to increased laser beam absorption. The observed correlation between the dimensions of the meltpool and the surface roughness was almost linear [9]. Sokolov et al. found that surface edge roughness at laser beam power more than 10 $\mathrm{kW}$ had a significant influence on penetration depth of butt-joint laser beam welding of structural steel [10]. The maximum penetration depth was achieved at $R a$ roughness of $6.3 \mu \mathrm{m}$ within the range from $R a=1.6$ to $8 \mu \mathrm{m}$ [10].

The aim of this paper was to study whether the surface roughness has influence on the weld joint porosity and to find out whether surface cleaning by machining can replace the effective, but expensive surface cleaning by a laser beam.

\section{METHODS}

An aluminium-lithium alloy AW2099 was welded in the form of a sheet with a thickness of $3 \mathrm{~mm}$ in the experiment. The chemical composition of AW2099 is shown in Tab. 1.

Prior to the welding process, the surface of the material was milled at 12 locations with different milling parameters to achieve different levels of roughness. Selected geometrical characteristics of surfaces $(R a, R q$, $R z$ ) were determined on milled surfaces (Tab. 2). The milling depth was constantly $0.5 \mathrm{~mm}$. The resulting thickness of the welded material after the milling process was $2.5 \mathrm{~mm}$. The milled material with the designation of the individual samples is shown in Fig. 5.

Table 1 Typical chemical composition of AW 2099 (Smiths metals centre, 2018)

\begin{tabular}{|c|c|c|c|c|c|c|c|c|}
\hline & $\mathrm{Cu}$ & $\mathrm{Li}$ & $\mathrm{Zn}$ & $\mathrm{Mg}$ & $\mathrm{Mn}$ & $\mathrm{Zr}$ & $\mathrm{Ti}$ & $\mathrm{Al}$ \\
\hline $\mathrm{Min}$ & 2.4 & 1.6 & 0.4 & 0.1 & 0.1 & 0.05 & 0 & Bal. \\
\hline Max & 3.0 & 2.0 & 1.0 & 0.5 & 0.12 & 0.1 & 0.1 & Bal. \\
\hline
\end{tabular}

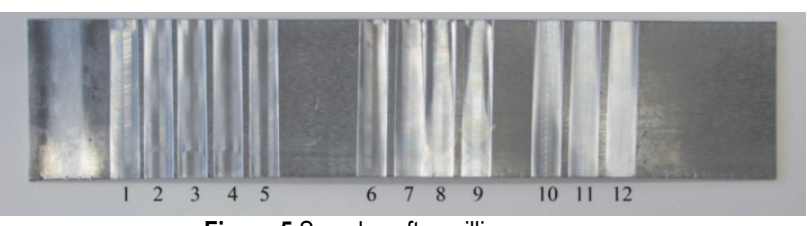

Figure 5 Samples after milling process

Surface roughness was measured using Mitutoyo SJ210 device (Fig. 6).

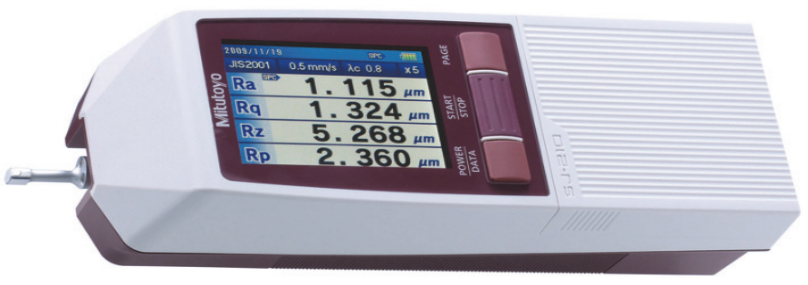

Figure 6 Mitutoyo SJ-210 device

After roughness measurement 6 machined and 1 brushed were selected as some roughness obtained by machining was very similar. Based on resulting roughness, samples $0,1,2,3,4,5,12$ were further analysed.

Tab. 2 describes the parameters for machining and obtained values of roughness. Fig. 7 documents the welding setup using self-designed welding jig capable of shielding the weld root during welding. Argon was used as a shielding gas covering the surface and helium for root because of their density and potentiality to escape from the molten pool.

Weld joint samples were cut out for computer tomography. Same dimensions of all samples were used in order to get the same perspective on porosity of the same representative length. Cutting was realised on manual abrasive cutter with water cooling from Buehler manufacturer.

Table 2 Parameters of milling and resulting roughness

\begin{tabular}{|c|c|c|c|c|c|c|c|c|}
\hline Sample & $\begin{array}{c}a_{\mathrm{p}} \\
/ \mathrm{mm}\end{array}$ & $\begin{array}{c}v_{\mathrm{c}} \\
/ \mathrm{m} \cdot \min ^{-1}\end{array}$ & $\begin{array}{c}n \\
/ \text { ot } \cdot \min ^{-1}\end{array}$ & $\begin{array}{c}f_{\mathrm{z}} \\
/ \mathrm{mm}\end{array}$ & $\begin{array}{c}v_{\mathrm{f}} \\
/ \mathrm{mm} \cdot \min ^{-1}\end{array}$ & $\begin{array}{l}R a \\
/ \mu \mathrm{m}\end{array}$ & $\begin{array}{l}R q \\
/ \mu \mathrm{m}\end{array}$ & $\begin{array}{l}\mathrm{Rz} \\
/ \mu \mathrm{m}\end{array}$ \\
\hline 1 & 0.5 & 500 & 7958 & 0.01 & 318 & 0.752 & 0.894 & 4.121 \\
\hline 2 & 0.5 & 500 & 7958 & 0.1 & 3183 & 5.926 & 6.981 & 26.037 \\
\hline 3 & 0.5 & 500 & 7958 & 0.15 & 4775 & 6.922 & 8.067 & 30.741 \\
\hline 4 & 0.5 & 500 & 7958 & 0.2 & 6366 & 9.124 & 10.837 & 42.128 \\
\hline 5 & 0.5 & 500 & 7958 & 0.05 & 1592 & 3.565 & 4.629 & 19.00 \\
\hline 6 & 0.5 & 500 & 7958 & 0.083 & 2642 & 5.558 & 6.897 & 25.358 \\
\hline 7 & 0.5 & 500 & 7958 & 0.083 & 2642 & 8.812 & 10.437 & 36.426 \\
\hline 8 & 0.5 & 500 & 7958 & 0.045 & 1432 & 5.689 & 6.460 & 22.105 \\
\hline 9 & 0.5 & 500 & 7958 & 0.04 & 1273 & 5.093 & 5.780 & 20.083 \\
\hline 10 & 0.5 & 500 & 7958 & 0.22 & 7003 & 11.514 & 14.957 & 61.706 \\
\hline 11 & 0.5 & 500 & 7958 & 0.24 & 7640 & 10.883 & 13.495 & 54.131 \\
\hline 12 & 0.5 & 500 & 7958 & 0.175 & 5571 & 14.957 & 55.829 & 55.829 \\
\hline
\end{tabular}

$a_{\mathrm{p}}$ - axial depth of cut, $v_{\mathrm{c}}$ - cutting speed, $n$ - rotational speed, $f_{\mathrm{z}}$ - feed per tooth, $v_{\mathrm{f}}$ - feed velocity 


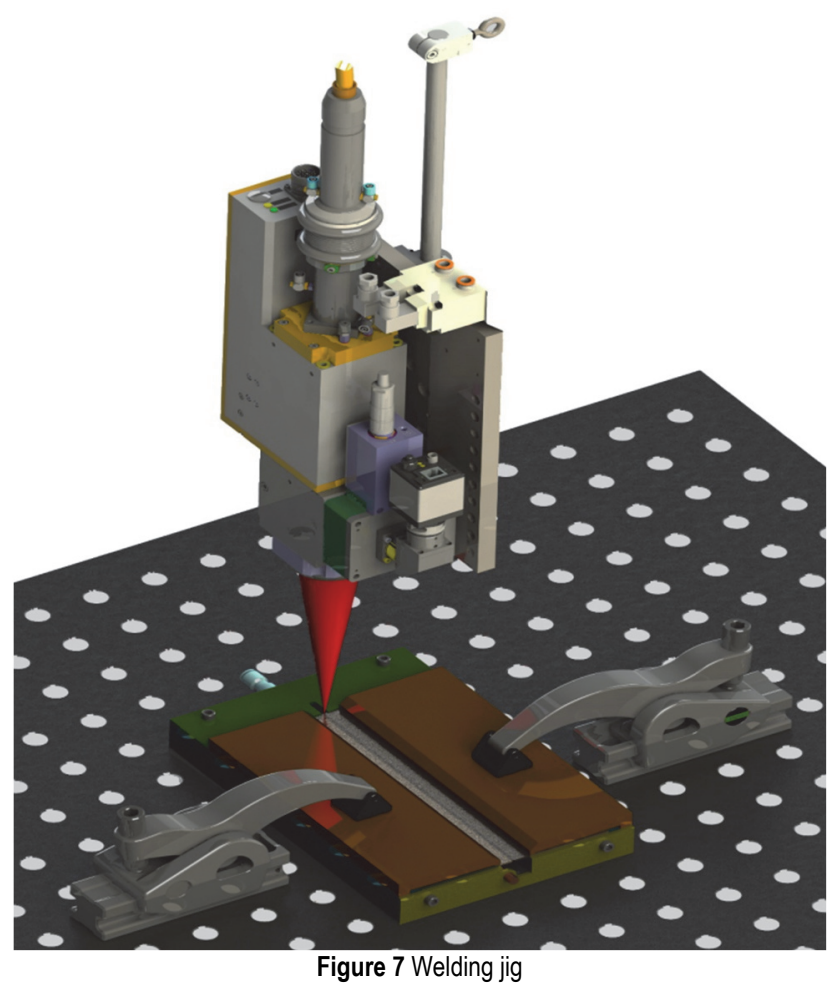

Scanning of samples was realised by Zeiss Metrotom 1500 computer tomograph (Fig. 8) to obtain 3D model. The device parameters are provided in Tab. 3 .

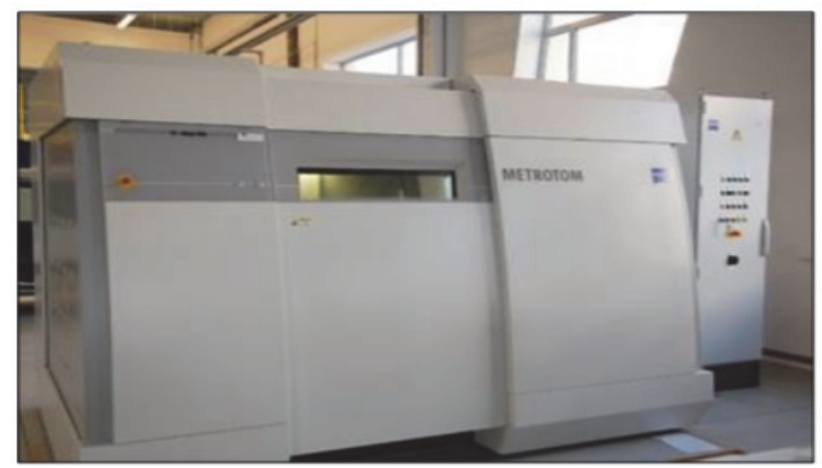

Figure 8 ZeissMetrotom 1500 computer tomograph

Table 3 Parameters range for Metrotom 1500

\begin{tabular}{|c|c|}
\hline Tube voltage, tube power & $225 \mathrm{kV}, 500 \mathrm{~W}$ \\
\hline Tube type & Open X-ray technology \\
\hline Source/detector distance & $1500 \mathrm{~mm}$ \\
\hline Measuring range & dia. $350 \times 300 \mathrm{~mm}$ \\
\hline Detector resolution & $2048 \times 2048 \mathrm{Px}$ \\
\hline
\end{tabular}

The porosity was analysed using VG Studio MAX (Fig. 9). Based on density differences inside the model it determines the amount of materials or pores.

\section{EXPERIMENTAL WORK AND RESULTS}

Welding was realised according to the methodology, using the parameters given in Tab. 3. Since the porosity was determined based on surface roughness the welding parameters were the same for all samples. Fig. 9 shows the $5 \mathrm{~cm}$ cut-outs from the middle part of weld joints, ready for CT scanning.

All welded joints proved stable welding process with full penetration and even weld width along full weld length. The weld bead exhibited a small concavity because of high parameters and welding without the filler material. Weld joint surface and root were smooth without any abnormalities.
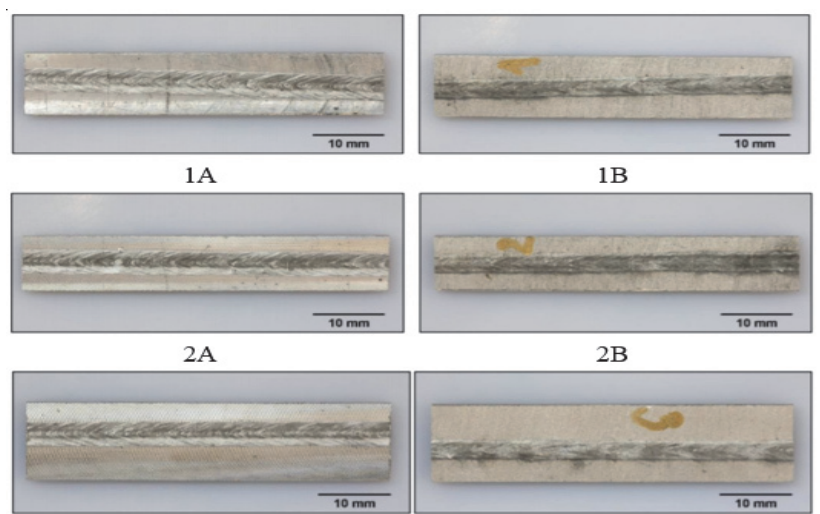

$3 \mathrm{~A}$
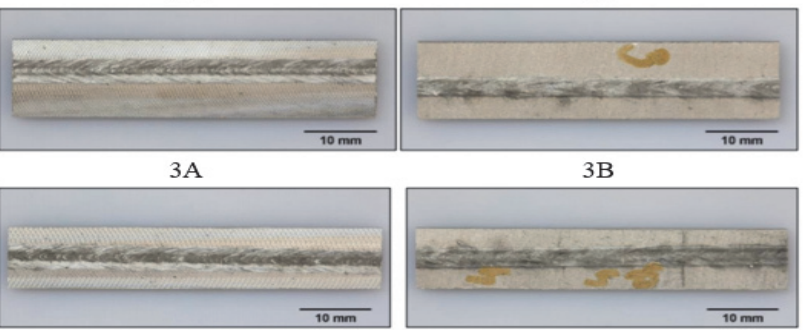

$4 \mathrm{~A}$

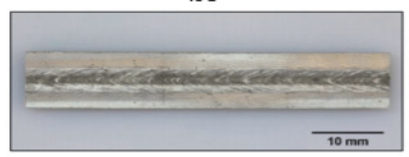

$5 \mathrm{~A}$

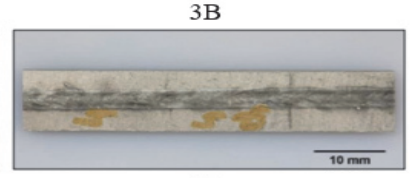

$4 B$

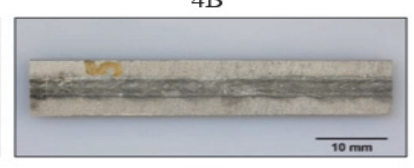

$5 \mathrm{~B}$

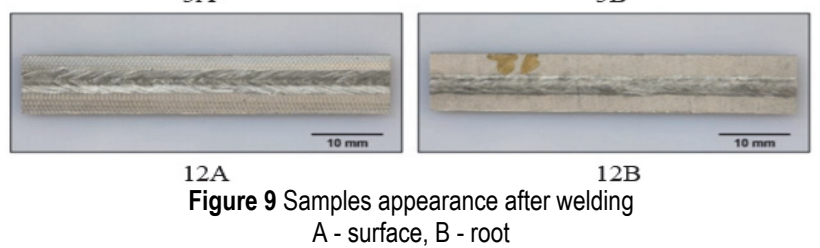

Fig. 10 documents the porosity measurement as an output from VG Studio. This analysis was realised for all 7 samples specified in methodology after the surface roughness measurement. VG studio analysed all pores present in the whole volume of sample, showing the amount and size of all pores found.

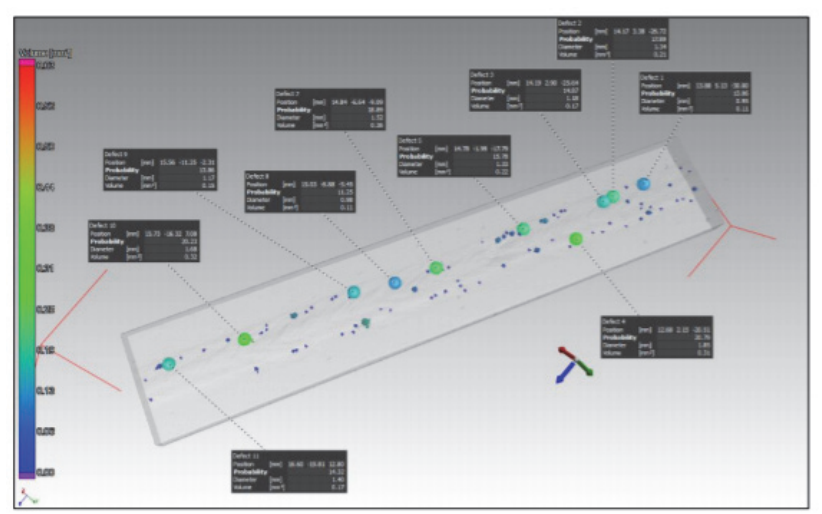

Figure 10 Porosity analysis in VG Studio

Most of the porosity was found near the fusion line of weld joints. The size (diameter) of pores in all samples varied from 0.9 up to $1.87 \mathrm{~mm}$. Any correlation between the surface roughness and size of the pores was not observed since almost all samples revealed the same size range. 
Analysis of variance (Fig. 11) was realised to determine the dependence of surface roughness on overall porosity volume using GraphPad Prism 8 software.
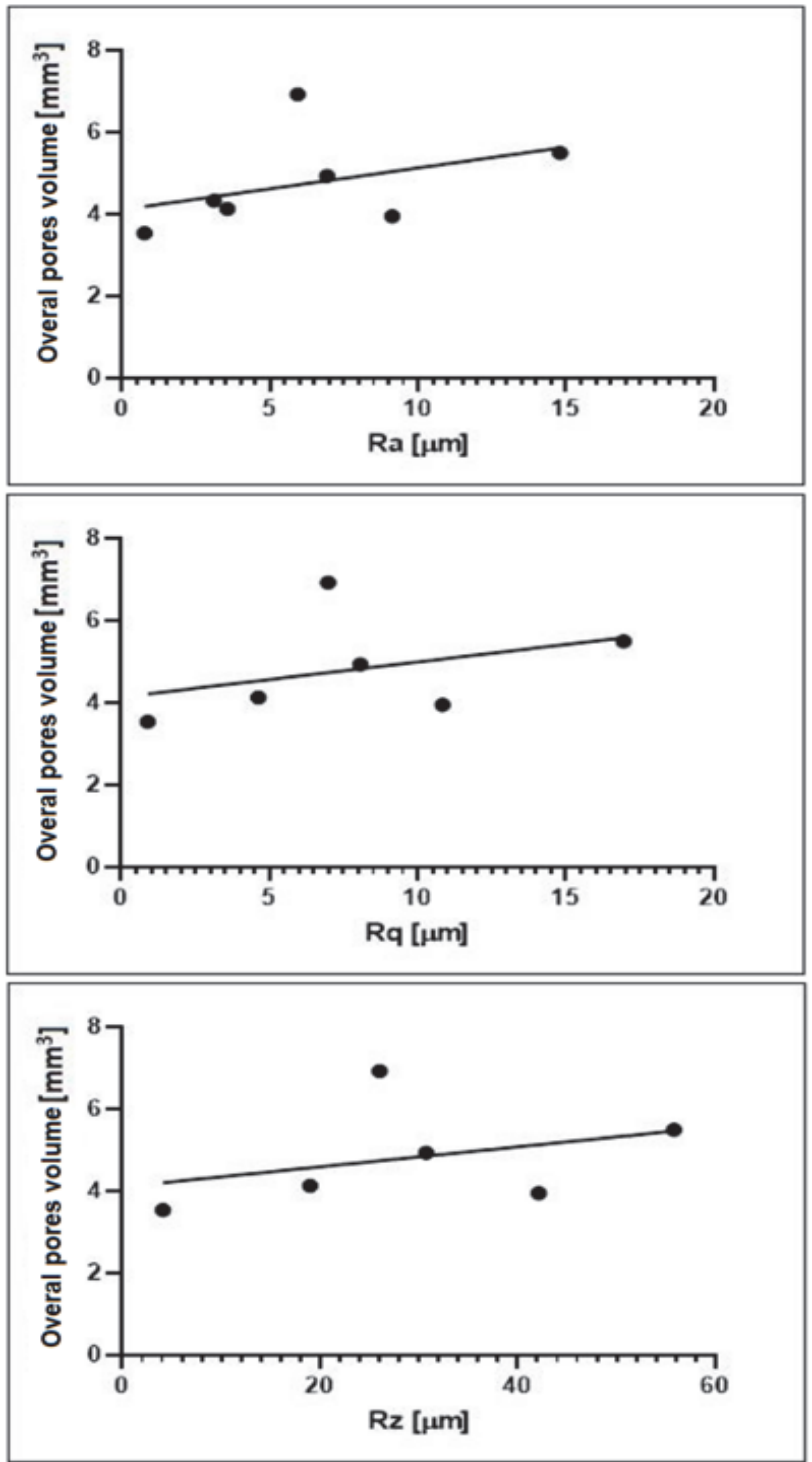

Figure 11 Graphical dependence of surface roughness on overall pores volume

Tab. 4 shows overall volume of all pores in particular sample.

Table 4 Surface characteristics after milling process

\begin{tabular}{|c|c|c|}
\hline Sample & $\begin{array}{l}\text { Overall porosity volume } \\
\qquad / \mathrm{mm}^{3}\end{array}$ & $\begin{array}{l}\text { Overall surface of pores } \\
\qquad / \mathrm{mm}^{2}\end{array}$ \\
\hline 0 (brushed) & 4.32 & 67.15 \\
\hline 1 & 3.53 & 95.31 \\
\hline 2 & 6.92 & 176.54 \\
\hline 3 & 4.93 & 72.29 \\
\hline 4 & 3.94 & 109 \\
\hline 5 & 4.12 & 105.38 \\
\hline 12 & 5.49 & 147.84 \\
\hline
\end{tabular}

Analysis showed that the dependence of roughness on surface roughness is insignificant. Second ANOVA analysis was realised to determine the dependence of surface roughness on overall pores surface.

Even in this case the influence of parameters was insignificant. There is no dependence between overall surface of pores and surface roughness within the observed roughness range.
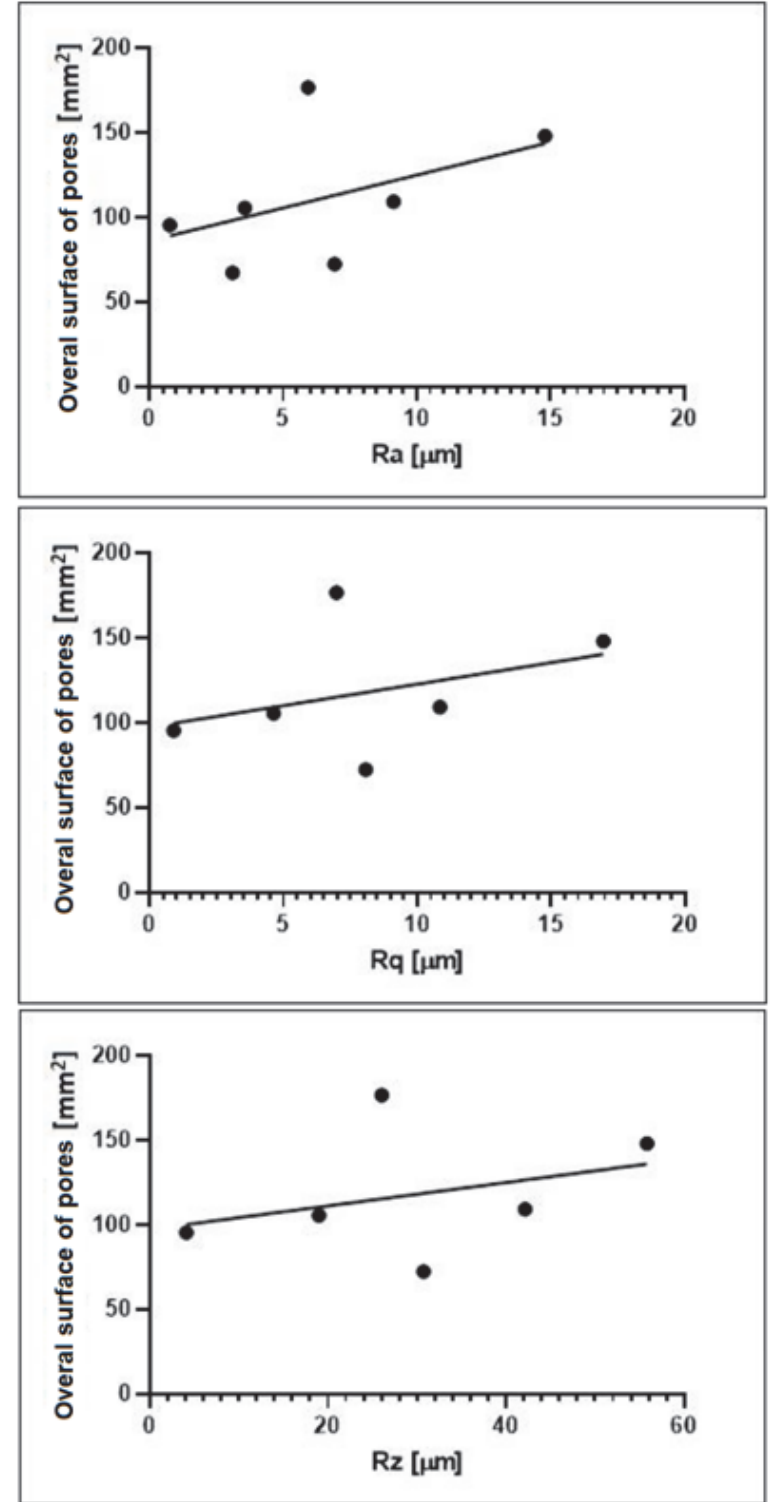

Figure 12 Graphical dependence of surface roughness on overall pores surface

\section{CONCLUSION}

The experiment was focused on finding the dependences between porosity and surface roughness in aluminium-lithium welded joints produced by laser beam welding. Porosity on prepared samples was analysed and quantified using ZEISS Metrotom computer tomograph. Analysis of Variance was used to determine the dependence between porosity and surface roughness of samples. The results showed that none of monitored factors was statistically significant so the dependences between parameters are random.

\section{Acknowledgements}

This paper was supported by the Scientific Grant Agency of the Ministry of Education of the Slovak Republic APVV-0248/12 project.

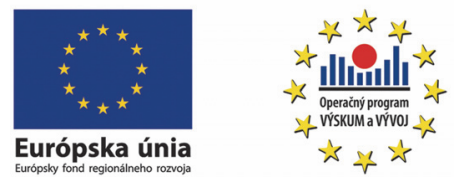




\section{REFERENCES}

[1] Cong, Z., Honggeng, L., Genyu, C., Gang, W., \& Zizhao, S. (2020). Effect of single pulsed picosecond and 100 nanosecond laser cleaning on surface morphology and welding quality of aluminium alloy. Optics \& Laser Technology, 127, 106197, ISSN 0030-3992. https://doi.org/10.1016/j.optlastec.2020.106197

[2] Wu, T. \& Shanglu, Y. (2020). Weld zone porosity elimination process in remote laser welding of AA5182-O aluminum alloy lap-joints. Journal of Materials Processing Technology, 286, 116826, ISSN 0924-0136. https://doi.org/10.1016/j.jmatprotec.2020.116826

[3] Shangren, L., Gaoyang, M., \& Chunming, W. (2020). A study on laser beam oscillating welding characteristics for the 5083 aluminum alloy: Morphology, microstructure and mechanical properties. Journal of Manufacturing Processes, 53, 12-20, ISSN 1526-6125. https://doi.org/10.1016/j.jmapro.2020.01.018

[4] Tongtong, L., Zhongyan, M., Renzhi, H., \& Shengyong, P. (2019). Sinusoidal oscillating laser welding of 7075 aluminum alloy: Hydrodynamics, porosity formation and optimization. International Journal of Heat and Mass Transfer, 140, 346-358, ISSN 0017-9310. https://doi.org/10.1016/j.ijheatmasstransfer.2019.05.111

[5] Jia, L., Hongyin, Z., Zhong, L., Wenfu, C., \& Yan, S. (2019). Effect of ultrasonic power on porosity, microstructure, mechanical properties of the aluminum alloy joint by ultrasonic assisted laser-MIG hybrid welding. Optics \& Laser Technology, 119, 105619, ISSN 0030-3992. https://doi.org/10.1016/j.optlastec.2019.105619.

[6] Xiaohui, H., Zhibin, Y., Yin, M., Chunyuan, S., \& Zhibin, X. (2020). Porosity distribution and mechanical response of laser-MIG hybrid butt welded 6082-T6 aluminum alloy joint. Optics \& Laser Technology, 132, 106511, ISSN 00303992. https://doi.org/10.1016/j.optlastec.2020.106511

[7] Mumin, S. (2008). Effect of surface roughness on weldability in aluminium sheets joined by cold pressure welding. Industrial Lubrication and Tribology. https://doi.org/10.1108/00368790810895187

[8] Hyeonggeun, J., Dongcheol, K., Munjin, K., Junhong, P., \& Young-Min, K. (2019). Effects of Surface Roughness and Force of Electrode on Resistance Spot Weldability of Aluminum 6061 Alloy. Applied Sciences, 9. https://doi.org/10.3390/app9193958

[9] Obeidi, M., Mccarthy, E., Ubani, S. I., \& Brabazon, D. (2019). Effect of Surface Roughness on $\mathrm{CO}_{2}$ Laser Absorption by $316 \mathrm{~L}$ Stainless Steel and Aluminum. Materials Performance and Characterization. 8(6). https://doi.org/10.1520/MPC20180091

[10] Sokolov, M., Salminen, A., Somonov, V., \& Kaplan, A. (2012). Laser welding of structural steels: Influence of the edge roughness level. Optics \& Laser Technology, 44, 20642071. https://doi.org/10.1016/j.optlastec.2012.03.025
Milan MARÔNEK, Prof. Ing. PhD

Slovak University of Technology in Bratislava,

Faculty of Materials Science and Technology in Trnava,

Paulínska 16, 91724 Trnava, Slovakia

E-mail: milan.maronek@stuba.sk

Filip ŠUGRA, Ing,

Slovak University of Technology in Bratislava,

Faculty of Materials Science and Technology in Trnava,

Paulínska 16, 91724 Trnava, Slovakia

E-mail: filip.sugra@stuba.sk

Michaela KRITIKOS, Ing. PhD

Slovak University of Technology in Bratislava,

Faculty of Materials Science and Technology in Trnava,

Paulínska 16, 91724 Trnava, Slovakia

E-mail: michaela.kritikos@stuba.sk

Dr. sc. Ivan SAMARDŽıć, Full Professor

Mechanical Engineering Faculty in Slavonski Brod, University of Slavonski Brod, Trg I.B. Mažuranić 2, Slavonski Brod, Croatia

E-mail: isamardzic@unisb.hr

Dejan MARIĆ, PhD

Mechanical Engineering Faculty in Slavonski Brod, University of Slavonski Brod, Trg I.B. Mažuranić 2, Slavonski Brod, Croatia

E-mail:dmaric@unisb.hr

\section{Contact information:}

\section{Michaela LOPATKOVÁ, Ing}

Slovak University of Technology in Bratislava,

Faculty of Materials Science and Technology in Trnava,

Paulínska 16, 91724 Trnava, Slovakia

E-mail: michaela.lopatkova@stuba.sk

Jozef BÁRTA, Ing. PhD

(Corresponding author)

Slovak University of Technology in Bratislava,

Faculty of Materials Science and Technology in Trnava,

Paulínska 16, 91724 Trnava, Slovakia

E-mail: jozef.barta@stuba.sk 